\title{
Self-Reported Symptoms and Concerns in Long-Term Survivors Attending Follow-Up Visits after Hematopoietic Stem Cell Transplantation: A Cross- Sectional Single Center Evaluation in Switzerland
}

\section{Monika Kirsch ${ }^{1}$, Jörg Halter ${ }^{2}$ and Sabina De Geest ${ }^{3 *}$}

${ }^{1}$ Department of Hematology, University Hospital Basel, Petersgraben 4, 4031 Basel, Switzerland

${ }^{2}$ Center for Health Services and Nursing Research, Katholieke Universiteit Leuven, Kapucijnenvoer 35, 3000 Leuven, Belgium

${ }^{3}$ Institute of Nursing Science, University of Basel, Bernoullistrasse 28, 4056 Basel, Switzerland

\begin{abstract}
Background: Health status self-reports are increasingly recognized as an important source of key follow-up data after hematopoietic stem cell transplantation (HSCT).

Purpose: The purpose of this study was to evaluate the occurrence of self-reported symptoms and concerns in longterm survivors and compare their prevalence's between allogeneic and autologous transplant recipients with various post-HSCT follow-up lengths.

Interventions/Methods: This cross-sectional survey included a convenience sample of 226 autologous and allogeneic HSCT recipients (54\% male; 1 to 26 (median 6) years post-transplant) treated as outpatients by the multidisciplinary team of a Swiss stem cell transplant ambulatory. Symptoms and concerns were measured by a selfdeveloped self-report questionnaire.

Results: The median number of self-reported physical symptoms per patient was 5(IQR 4-10), the most frequent being dry skin $(47.8 \%)$, tiredness $(42 \%)$, and dry eyes $(42 \%)$. The most commonly cited concerns were difficulties managing stressful emotional situations $(23.9 \%)$, anxiety regarding relapse $(22.1 \%)$ and memory disturbance $(21.2 \%)$. There were no notable differences in appraisal of performance and number of symptoms between different time groups.

Conclusion: The high frequency of self-reported symptoms and concerns in long-term survivors indicates a need for continuous monitoring by stem cell transplant follow up clinics, which would allow timely and effective interventions to prevent or alleviate late effects.

Implications for Practice: There seems to be good opportunity for health professionals to support long-term survivors by using self-report as clinical tool in follow-up care. Sharing information about problems and symptoms patients face post-treatment will benefit both professionals and patients.
\end{abstract}

Keywords: Stem cell transplantation; Survivorship; Late effects; Follow-up; Self report; Symptoms

\section{Introduction}

Hematopoietic Stem Cell Transplantation (HSCT) is a curative, intensive treatment for hematological and lymphoid cancers, and also for other autoimmune and genetic disorders [1]. Despite advances in procedure and supportive care, transplant related morbidity and mortality remains high. Many survivors have to adapt to physical complications and chronic health conditions - referred to here as 'late effects'- associated with high distress, poorer long-term adjustment and shorter survival $[2,3]$. Comprehensive follow-up of long-term survivors after HSCT is crucial, as the cure or control of the underlying disease may not be accompanied by a full restoration of health and a return to normality [4]. As many late effects are manifested in patient-perceptible symptoms, patient self-reporting, which captures issues assessable only or predominantly through patients' perceptions, is increasingly recognized as an important source of subjective information [5]. However, empirical evidence shows that many clinicians systematically downgrade or fail to note the severity of patient-reported symptoms, which may contribute to preventable late effects [6]. Therefore, a system of self-reporting allows healthcare professionals and patients to better communicate and understand each other, facilitates informed decisions regarding symptom management and treatment, and may even allow prevention of some late effects, it is recommended to treat self-reporting as a major element of follow-up care $[7,8]$. To provide effective symptom management for this population, nurses and physicians need an understanding of patients' specific problems and symptoms. Integrating self-reporting as a clinical patient management tool can help that patients prepare themselves for the consultation with the physician or nurse so that topics can be discussed in a structured format.

As suggested by psychosocial transition theory, [9] this study views patients' confrontations with serious illness, its treatment and consequences as major life experiences that require them 'to restructure their ways of looking at the world' and adapt their plans and actions accordingly. We developed the HSCT Assist Model to organize factors related to post-transplant life after the end of acute treatment. This study's framework is based on psychosocial transition theory, integrating evidence from the literature [10-22] with clinically known factors for the development of late effects (e.g., disease, treatment, transplant complications). The model summarizes nine domains of ongoing survivorship issues assessable via patient self-reporting. In

*Corresponding author: Sabina De Geest, Institute of Nursing Science, University of Basel, Bernoullistrasse 28, CH-4056 Basel, Tel: +41(0)61 26730 40; Fax : +41(0)61 26709 55; E-mail: sabina.degeest@unibas.ch

Received May 10, 2012; Accepted June 25, 2012; Published June 27, 2012

Citation: Kirsch M, Halter J, Geest SD (2012) Self-Reported Symptoms and Concerns in Long-Term Survivors Attending Follow-Up Visits after Hematopoietic Stem Cell Transplantation: A Cross-Sectional Single Center Evaluation in Switzerland. J Nurs Care 1:116. doi:10.4172/2167-1168.1000116

Copyright: (C) 2012 Kirsch M, et al. This is an open-access article distributed under the terms of the Creative Commons Attribution License, which permits unrestricted use, distribution, and reproduction in any medium, provided the original author and source are credited. 
Citation: Kirsch M, Halter J, Geest SD (2012) Self-Reported Symptoms and Concerns in Long-Term Survivors Attending Follow-Up Visits after Hematopoietic Stem Cell Transplantation: A Cross-Sectional Single Center Evaluation in Switzerland. J Nurs Care 1:116. doi:10.4172/21671168.1000116

Page 2 of 7

addition to guidance for comprehensive assessment of survivorship issues, this provides a basis for later analysis (Figure 1).

Previous research using patient self-reporting focused mainly on the measurement of quality of life. However, it did not describe findings generated by measures employed in the clinical follow-up setting to assess common symptoms that might be linked to co-morbidities or late effects, i.e., conditions that would necessitate ongoing treatment by the multidisciplinary follow-up team. To our knowledge, there is no research describing results of routinely used self-report in HSCT long-term follow-up care. Another question that has recently been under discussion is whether autologous HSCT patients require the same follow-up care and surveillance as allogeneic HSCT recipients. Although it is commonly stated that autologous HSCT recipients need fewer follow-ups than allogenic recipients; some clinicians, however, put this in question considering the older age of auto HSCT recipients and the rising number of treatment indications.

The purpose of the current study was threefold: (1) to describe allogeneic and autologous HSCT recipients' self-reported symptoms and concerns during routine follow-up; (2) to determine differences in the prevalence of physical or psychological symptoms between allogeneic and autologous transplanted patients; and (3) to explore differences among groups in different post-HSCT follow-up periods.

\section{Methods}

\section{Design}

We used a cross-sectional study design analyzing data of a routine follow-up survey implemented during daily clinical practice at each yearly follow-up visit in a single HSCT center in Switzerland.

\section{Sample and setting}

All patients attending 2008 yearly follow-up consultations in the

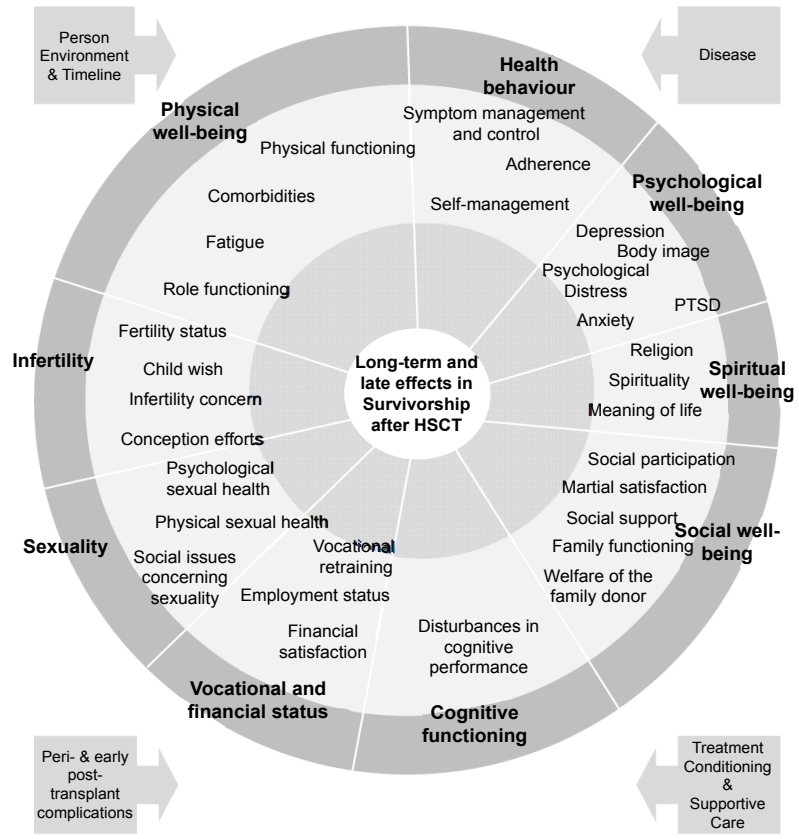

Figure 1: The Hematopoietic Stem Cell Transplantation-Assist Model illustrates the nine overall domains in which long-term survivors might experience alterations and show a need for assistance from the health care provider. Within each domain, the concepts give more specific information about the patient's condition. Concepts are measured via indicators/symptoms. A wide range of indicators exist: however, none are displayed in this overview. The four arrow boxes depict factors which influence alterations decisively.
Haematology Department of the University Hospital Basel (USB) were invited to fill out a self-developed survey. Patient inclusion criteria for the present study were: $\geq$ one year after autologous or allogeneic HSCT; $\geq 18$ years of age at the time of follow-up; and completion of the questionnaire. Patients who did not return their questionnaires were considered non-responders.

The USB is located in the German-speaking part of Switzerland, but the hematology clinic's patients come from all over the country, and therefore, may also be mother-tongue speakers of French, Italian, Romansch or any of a broad range of foreign languages. As health insurance is mandatory, all are insured and eligible for regular lifelong follow-up care. After their first year of survival, all patients are requested to return to the center for yearly check-ups. The outpatient care team included one senior physician, two junior physicians and 12 registered nurses sharing 7.5 full time positions.

\section{Variables and measurement}

Demographic and clinical variables: Patients' demographic and clinical data were retrieved from medical files and an electronic transplant database. Variables included gender, age, native language, marital status and current working status, coverage of disability insurance and years of post-HSCT follow-up. Patients' follow-up times were categorized in 4 groups: 1 - 2 years; $3-5$ years; 6-9 years; and $\geq 10$ years. Clinical variables included hematological diagnosis, type and source of transplant, donor relationship, whether total body irradiation was used or not, Karnofsky Performance Status (KPS) [23] and presence of chronic GvHD, scored according to the National Institute of Health grading system [24].

\section{Symptoms and concerns}

The clinical survey (Table 1) used to assess symptoms and concerns possibly associated with late effects were developed in 2002 by the USB's multidisciplinary HSCT follow-up healthcare team. It was designed to gather subjective information to inform clinicians about the patient's perspective encountered during yearly check-up visits. Thus far, validation of the survey has been limited to face validity. In order to further assess its content validity we reviewed its content using the nine domains of the HSCT Assist model as a framework (Figure 1). In the survey, only seven of the nine domains were partly captured via 70 items for women and 66 items for men. 'Spiritual well-being' and 'health behaviour' were not addressed. Except for one open question (Kind of changes experienced in spousal relationship after HSCT), items were scored as "yes" or "no". The time frame for responses was the previous year. The survey exists in French and German (Table 1).

\section{Data collection}

This study was approved by the local ethics committee. As part of a standard clinical follow-up, survey forms were mailed to patient's homes prior to their annual follow-up appointments. Responders then brought their completed forms to their check-ups and gave them to their treating physicians, who referred to the survey as a source of information during the clinical visit. Patients were asked for consent and informed that their responses would be used for research purposes. Confidentiality was also assured. Completed surveys were added to the patients' medical files. For data entry, questionnaires were retrieved from medical files by the first author and one research assistant. Data were entered manually to an anonymized database and checked for consistency and accuracy.

\section{Data analysis}

Descriptive analysis involved frequencies and calculations of central tendencies and distributions as appropriate. Characteristics of responders and non-responders were compared depending on 
Citation: Kirsch M, Halter J, Geest SD (2012) Self-Reported Symptoms and Concerns in Long-Term Survivors Attending Follow-Up Visits after Hematopoietic Stem Cell Transplantation: A Cross-Sectional Single Center Evaluation in Switzerland. J Nurs Care 1:116. doi:10.4172/21671168.1000116

Page 3 of 7

measurement level and distribution using the Student's T-Test, the Mann-Whitney U-Test and the Chi-Square Test. Comparison of the numbers of symptoms reported by autologous and allogeneic patients used the Mann-Whitney U-Test. Differences between the two groups' responses to individual items were examined with the Chi-Square-Test. Regarding the numbers of physical and psychological symptoms, as well as appraisals of regained pre-transplant performance, differences between groups with different follow up times were examined respectively with the Kruskall-Wallis $\mathrm{H}$-test and the Chi-Square test. Statistical significance was set at alpha $=0.05$. In order to control for multiple testing and to keep the proportion of false-positive results under 5\%, we calculated Q-values in a series of post-hoc tests in which we compared the prevalence of single symptoms in autologous and allogeneic patients [25]. Data analysis was performed using SPSS 16.0.

\section{Results}

\section{Patient characteristics}

In total, 326 eligible patients visited the outpatient clinic for annual follow-up consultations in 2008. Of these, 226 (69.3\%) returned completed surveys. There was only one significant difference between patients who responded to the survey $(226 / 326)$ and those who did not (100/326): a clear majority of responders spoke German or French as a

\begin{tabular}{|c|c|}
\hline \multicolumn{2}{|c|}{ Physical well-being (49 items on physical symptoms) } \\
\hline Skin/hair & $\begin{array}{l}\text { Dry skin, skin itching, alopecia/hair loss, skin rash, skin } \\
\text { changes }\end{array}$ \\
\hline Eyes & Dry eyes, light sensitivity, blurred vision, burning eyes \\
\hline Otolaryngology & Common cold, hardness of hearing, sinusitis, ear pain \\
\hline Mouth & $\begin{array}{l}\text { Dry mouth, caries, loss of taste, mouth ulcers, tongue } \\
\text { burning, fever blisters, toothache, open lesions, gum } \\
\text { bleeding }\end{array}$ \\
\hline Lung & Breathing difficulty, cough, increased sputum \\
\hline Cardiovascular & $\begin{array}{l}\text { Hypertension, irregular pulse, chest pain on exertion, } \\
\text { swollen legs }\end{array}$ \\
\hline Gastrointestinal & $\begin{array}{l}\text { Diarrhoea, abdominal pain, nausea/vomiting, pyrosis, } \\
\text { loss of appetite, constipation, weight loss, rectal bleeding }\end{array}$ \\
\hline Urogenital & $\begin{array}{l}\text { Incontinence, burning on urination, haematuria, cystitis, } \\
\text { nephritis }\end{array}$ \\
\hline Neurological & Nervousness, insomnia, shivering, dizziness, palsy \\
\hline Single symptom items & Fatigue, infections treated with antibiotics \\
\hline \multicolumn{2}{|c|}{ Psychological well-being (5 items on psychological symptoms) } \\
\hline & $\begin{array}{l}\text { Listlessness; diminished emotional capacity; increased } \\
\text { aggression; anxiety regarding relapse, sadness }\end{array}$ \\
\hline \multicolumn{2}{|c|}{ Social well-being ( 3 items) } \\
\hline & $\begin{array}{l}\text { - Have there been changes in your spousal relation- } \\
\text { ship due to HSCT? } \\
\text { - If yes, what kind of changes have you experienced? } \\
\text { (text) } \\
\text { Do you have problems in connecting with social } \\
\text { groups? }\end{array}$ \\
\hline \multicolumn{2}{|c|}{ Vocational and financial status ( 4 items) } \\
\hline & $\begin{array}{l}\text { - Re-uptake of employment post-HSCT; } \\
\text { - } \text { Change of profession resulting from HSCT; } \\
\text { - Occupational re-training done; } \\
\text { Desire to speak with an aide about financial problems } \\
\text { after HSCT }\end{array}$ \\
\hline \multicolumn{2}{|c|}{ Cognitive functioning (1 item) } \\
\hline & Disturbance of memory \\
\hline \multicolumn{2}{|c|}{$\begin{array}{l}\text { Infertility \& Sexuality (Female: } 5 \text { items; male: } 1 \text { item; addressing both gender: } \\
3 \text { items) }\end{array}$} \\
\hline Female & $\begin{array}{l}\text { Diminished vaginal lubrication, itching of vagina, in- } \\
\text { creased vaginal efflux, painful intercourse, hot flashes }\end{array}$ \\
\hline Male & Erectile dysfunction \\
\hline Both genders & $\begin{array}{l}\text { Loss of desire; desire to have children; wish to speak } \\
\text { with an expert about problems concerning sexuality }\end{array}$ \\
\hline
\end{tabular}

Table 1: List of items requested by the follow-up questionnaire. native language (71.9\% (German or French) versus 57.1\% (all others) $\mathrm{p}=0.03$ ). Responders also tended to have shorter follow-up times than non-responders (median 6 years, IQR 7.94, versus a median of 6; IQR 10.75; $\mathrm{p}=0.066$ ). Medical characteristics and demographics of included patients are shown in table 2 and 3.

\section{Self-reported symptoms and concerns}

Physical symptoms: One or more physical symptoms were reported by $90.3 \%$ of patients (204/226), with a median number of 5 (IQR 6). Patients in their first two years post-HSCT reported a median of 7 (IQR 6) symptoms; with 3 to 5 years, the median fell to 5 (IQR 8.25) symptoms; and while the 6 to 9 year patients reported a median of 6 (IQR 9) physical symptoms, the group with 10 or more years of follow-up experienced a median of only 4 (IQR 7) $(\mathrm{p}=0.256)$ (Figure 2).

Sorted by organ system, the patient sample reported symptoms relating to skin and hair (60.6\%); eye $(59.3 \%)$; oral/dental $(49.1 \%)$ neurological (44.7\%); cardiovascular (38.9\%); gastrointestinal (37.2\%); lung (32.3\%), otolaryngological (32.3\%) or urological (12.4\%) symptom (Table 4).

Three of the ten most frequently reported physical symptoms were indicated by over $40 \%$ of all patients: dry skin ( $47.8 \%)$, dry eyes (42\%) and tiredness $(42 \%)$. Seven more symptoms were reported by more than $20 \%$ of all patients: mouth dryness $(28.3 \%)$, breathing difficulty (24.3\%), light sensitivity (23.9\%), blurred vision (23\%), infections treated with antibiotics $(22.1 \%)$, common cold $(21.7 \%)$ and burning eyes (20.4\%).

Although, on average, allogeneic recipients stated slightly more physical symptoms than autologous recipients (median 6, IQR 8 vs. median 4.5 , IQR $6.77 ; \mathrm{p}=0.64$ ), the observed difference was not significant. Furthermore, as shown in figure 3, no notable differences were found between transplant groups regarding individual physical symptom items (Figure 3 ).

\begin{tabular}{|c|c|c|c|}
\hline Characteristics & Total $(\mathrm{N}=226)$ & Allo $(n=188)$ & Auto $(\mathrm{n}=38)$ \\
\hline Age at last HSCT; mean (SD) & $40.1(15.0)$ & $38.15(14.39)$ & $49.83(14.44)$ \\
\hline $\begin{array}{l}\text { Years after HSCT; median } \\
\text { (Range) }\end{array}$ & $6(1-26)$ & $6(2-11)$ & $5(2.75-8.25)$ \\
\hline Gender; male & $122(54 \%)$ & $102(54.3 \%)$ & $20(52.6 \%)$ \\
\hline \multicolumn{4}{|l|}{ Marital status } \\
\hline Married/cohabiting & $154(68.2 \%)$ & $128(68.1 \%)$ & $26(68.4 \%)$ \\
\hline Single/widowed/separated & $50(22.1 \%)$ & $43(22.9 \%)$ & $7(18.4 \%)$ \\
\hline Not documented & $22(9.7 \%)$ & $17(9 \%)$ & $5(13.2 \%)$ \\
\hline \multicolumn{4}{|l|}{ Native Language } \\
\hline German & $181(80.1 \%)$ & $150(79.8 \%)$ & $31(81.6 \%)$ \\
\hline French & $13(5.7 \%)$ & $11(5.9 \%)$ & $2(5.3 \%)$ \\
\hline Other & $32(14.2 \%)$ & $27(14.3 \%)$ & $5(13.1 \%)$ \\
\hline \multicolumn{4}{|l|}{ Current working status } \\
\hline Full time $^{a}$ & $73(32.3 \%)$ & $65(34.6 \%)$ & $8(21.1 \%)$ \\
\hline Part-time & $61(27 \%)$ & $54(28.7 \%)$ & $7(18.4 \%)$ \\
\hline Homemaker & $22(9.7 \%)$ & $16(8.5 \%)$ & $6(15.8 \%)$ \\
\hline Not working & $33(14.6 \%)$ & $32(17 \%)$ & $1(2.6 \%)$ \\
\hline Retired & $19(8.4 \%)$ & $9(4.8 \%)$ & $10(26.3 \%)$ \\
\hline Not documented & $18(8 \%)$ & $12(6.4 \%)$ & $6(15.8 \%)$ \\
\hline \multicolumn{4}{|l|}{ Receiving disability insurance $^{b}$} \\
\hline No disability insurance & $197(87.2 \%)$ & $161(85.6 \%)$ & $36(94.8 \%)$ \\
\hline Full Disability insurance & $21(9.3 \%)$ & $20(10.6 \%)$ & $1(2.6 \%)$ \\
\hline Partial Disability insurance & $8(3.5 \%)$ & $7(3.7 \%)$ & $1(2.6 \%)$ \\
\hline
\end{tabular}

Abbreviation: SD, standard deviation

aFull-time engagement means working at least 33 hours per week.

${ }^{b}$ Disability insurance includes paid sick leave, short-term disability benefits and long-term disability benefits.

Table 2: Demographic characteristics $(\mathrm{N}=226)$ 
Citation: Kirsch M, Halter J, Geest SD (2012) Self-Reported Symptoms and Concerns in Long-Term Survivors Attending Follow-Up Visits after Hematopoietic Stem Cell Transplantation: A Cross-Sectional Single Center Evaluation in Switzerland. J Nurs Care 1:116. doi:10.4172/21671168.1000116

Page 4 of 7

\begin{tabular}{|c|c|c|c|}
\hline & Total $(\mathrm{N}=\mathbf{2 2 6})$ & Allo $(n=188)$ & Auto $(n=38)$ \\
\hline \multicolumn{4}{|l|}{ Initial Diagnosis } \\
\hline AML & $40.1(15.0)$ & $56(29.8 \%)$ & $4(10.5 \%)$ \\
\hline ALL & $30(13.3 \%)$ & $27(14.4 \%)$ & $3(7.9 \%)$ \\
\hline CML & $41(18.1 \%)$ & $39(20.7 \%)$ & $2(5.3 \%)$ \\
\hline CLL & $9(4 \%)$ & $4(2.1 \%)$ & $5(13.2 \%)$ \\
\hline Plasma cell disorder & $28(12.4 \%)$ & $10(5.3 \%)$ & $18(47.8 \%)$ \\
\hline $\begin{array}{l}\text { Hodgkin or Non Hodgkin } \\
\text { lymphoma }\end{array}$ & $24(10.6 \%)$ & $21(11.2 \%)$ & $3(7.9 \%)$ \\
\hline Myelodysplastic syndrome & $14(6.2 \%)$ & $13(6.9 \%)$ & $1(2.6 \%)$ \\
\hline Myeloproliferative syndrome & $7(3.1 \%)$ & $7(3.7 \%)$ & 0 \\
\hline Aplastic anaemia & $10(4.4 \%)$ & $10(5.3 \%)$ & 0 \\
\hline $\begin{array}{l}\text { Autoimmune disease or inborn } \\
\text { error }\end{array}$ & $3(1.3 \%)$ & $1(0.5 \%)$ & $2(5.3 \%)$ \\
\hline \multicolumn{4}{|l|}{ Source of transplant } \\
\hline Bone marrow & $57(25.2 \%)$ & $56(29.8 \%)$ & $1(2.6 \%)$ \\
\hline Peripheral blood & $168(74.3 \%)$ & $131(69.7 \%)$ & 37 (97.4\%) \\
\hline Umbilical cord blood & $1(0.4 \%)$ & $1(0.5 \%)$ & 0 \\
\hline \multicolumn{4}{|l|}{ Total Body Irradiation ${ }^{a}$} \\
\hline Yes & $115(50.9 \%)$ & $111(59 \%)$ & $4(10.5 \%)$ \\
\hline \multicolumn{4}{|l|}{ No. of transplantations } \\
\hline 1 & $18(8 \%)$ & $12(6.4 \%)$ & $6(15.8 \%)$ \\
\hline$>1$ & $45(19.9 \%)$ & $39(20.7 \%)$ & $6(15.8 \%)$ \\
\hline \multicolumn{4}{|l|}{$\begin{array}{l}\text { Donor relationship in allogeneic } \\
\text { patients }(n=188)\end{array}$} \\
\hline $\begin{array}{l}\text { Identical sibling or matched } \\
\text { related }\end{array}$ & & $127(67.6 \%)$ & NA \\
\hline Syngen & & $6(3.2 \%)$ & NA \\
\hline Missmatched related & & $11(5.9 \%)$ & NA \\
\hline Unrelated & & $44(23.4 \%)$ & NA \\
\hline \multicolumn{4}{|l|}{ Active chronic GvHD $(n=188)^{b}$} \\
\hline Yes & & $72(38.3 \%)$ & NA \\
\hline No & & $102(54.3 \%)$ & NA \\
\hline Unclear or not documented & & $14(7.4 \%)$ & NA \\
\hline \multicolumn{4}{|l|}{ Karnofsky Score $^{c}$} \\
\hline $100 \%$ & $137(60.6 \%)$ & $112(59.6 \%)$ & $25(65.8 \%)$ \\
\hline $90-99 \%$ & $63(27.9 \%)$ & $55(29.3 \%)$ & $8(21 \%)$ \\
\hline $80-89 \%$ & $16(7.1 \%)$ & $12(6.4 \%)$ & $4(10.6 \%)$ \\
\hline$<80$ & $6(2.7 \%)$ & $5(2.6 \%)$ & $1(2.6 \%)$ \\
\hline Not documented & $4(1.8 \%)$ & $4(2.1 \%)$ & \\
\hline
\end{tabular}

Abbreviations: AML: Acute Myeloid Leukaemia; ALL: Acute Lymphoblastic Leukaemia, CML: Chronic Myeloid Leukaemia; CLL: Chronic Lymphocytic Leukaemia; GvHD: Graft versus Host Disease.

${ }^{\text {aP }}$ revalence of patients who had a total body irradiation in the conditioning regime with 12 Gray.

${ }^{\mathrm{b}}$ The GvHD grading scheme developed by the National Institutes of Health consensus development project on criteria for clinical trials in chronic GvHD, was used by rating physicians.

cKarnofsky Performance status (KPS) was rated by the physician at the annual follow-up visit and comprises an individual's health and physical functionality, based on a criteria related performance index rated from 100\% (normal function) to $10 \%$ (moribund).

Table 3: Medical characteristics $(\mathrm{N}=226)$.

Psychological well-being: One or more psychological concerns were indicated by $45.6 \%$ of patients $(104 / 226)$. The most common, claimed by $23.9 \%$ of patients, was managing stressful emotional situations, followed by anxiety regarding relapse (22.1\%) and sadness (13.7\%). Listlessness and increased aggression were mentioned by $11.1 \%$ each. Autologous and allogeneic patients did not differ regarding the median number of overall psychological symptoms $(\mathrm{p}=0.507)$. However, with increased follow-up time, patients of both transplant

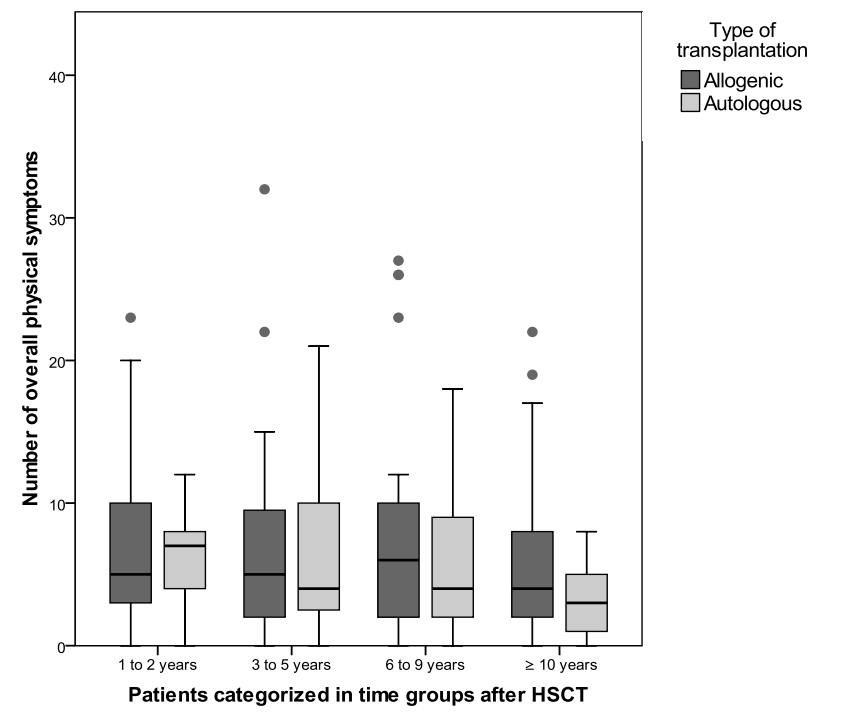

Figure 2: Median number of physical symptoms related to time-period of follow-up. Boxes include the distribution of numbers of symptoms between the $75^{\text {th }}$ and the $25^{\text {th }}$ percentile, with the thick line in each box representing the median number of symptoms. The lines extending above and below the boxes indicate the $90^{\text {th }}$ and $10^{\text {th }}$ percentile, respectively. Outliers are designated as ' $\because$ '. Patients are grouped by transplant type (allogeneic/autologous) and by period post-HSCT ( 1 to 2 years $(n=58) ; 3$ to 5 years $(n=54) ; 6$ to 9 years $(n=54)$ and $\geq 10(n=60))$

\begin{tabular}{|l|l|l|l|l|}
\hline & $\begin{array}{c}\text { Patients reporting } \geq 1 \\
\text { symptom in one organ } \\
\text { group a; } \mathbf{n}(\mathbf{\%})\end{array}$ & $\begin{array}{c}\text { Percentages of patients } \\
\text { classified by their reported } \\
\text { number of symptoms } \\
\text { Auto (n=38) }\end{array}$ \\
\hline Skin \& hair (5 items) & $137(60.6 \%)$ & $1-2$ & $3-4$ & $\geq 5$ \\
\hline Eyes (4 items) & $134(59.3 \%)$ & $41.8 \%$ & $6.6 \%$ & $2.2 \%$ \\
\hline Otolaryngology (4 items) & $73(32.3 \%)$ & $31 \%$ & $1.3 \%$ & 0 \\
\hline Oral/dental (9 items) & $111(49.1 \%)$ & $37.6 \%$ & $8 \%$ & $3.5 \%$ \\
\hline Lungs (3 items) & $73(32.3 \%)$ & $31 \%$ & $1.3 \%$ & 0 \\
\hline Cardiovascular (4 items) & $88(38.9 \%)$ & $35.8 \%$ & $3.1 \%$ & 0 \\
\hline Gastrointestinal (8 items) & $84(37.2 \%)$ & $28.3 \%$ & $7.1 \%$ & $1.8 \%$ \\
\hline Urological (5 items) & $28(12.4 \%)$ & $11.1 \%$ & $1.3 \%$ & 0 \\
\hline Neurological $(6$ items) & $101(44.7 \%)$ & $34.5 \%$ & $8.4 \%$ & $1.8 \%$ \\
\hline
\end{tabular}

apercentage is based on total population $(\mathrm{N}=226)$

Table 4: demonstrates numbers and prevalence of the symptoms indicated by patients regarding symptom groups.

types reported fewer psychological concerns. While in the first two years post-HSCT, $60.3 \%$ of patients reported at least one psychological concern (mean number of concerns 1.06, SD 1.18), that number fell after 3 to 5 years to $53.7 \%$ (mean 1, SD 1.32), after 6 to 9 years to $37 \%$ (mean 0.78 , SD 1.28) and after ten or more years to $31.7 \%$ (mean 0.47 , $\mathrm{SD} 0.83)(\mathrm{p}=0.007)$.

Cognitive functioning: Memory disturbance was reported by $21.2 \%$ of patients. No differences in the prevalence of memory problems were found between autologous and allogeneic transplant recipients $(p=0.368)$, or between groupings based on follow-up length $(p=0.173)$.

Vocational and financial well-being: After a median 5 years of follow-up, illness-related job changes were reported by $11 \%$ of patients (range: 1-25 years of follow-up), and participation in occupational retraining was noted by $8.4 \%$ (range 1-20 years of follow-up). A small minority $(5.3 \%)$ claimed current financial difficulties requiring the support of a social worker. 
Citation: Kirsch M, Halter J, Geest SD (2012) Self-Reported Symptoms and Concerns in Long-Term Survivors Attending Follow-Up Visits after Hematopoietic Stem Cell Transplantation: A Cross-Sectional Single Center Evaluation in Switzerland. J Nurs Care 1:116. doi:10.4172/21671168.1000116

Page 5 of 7

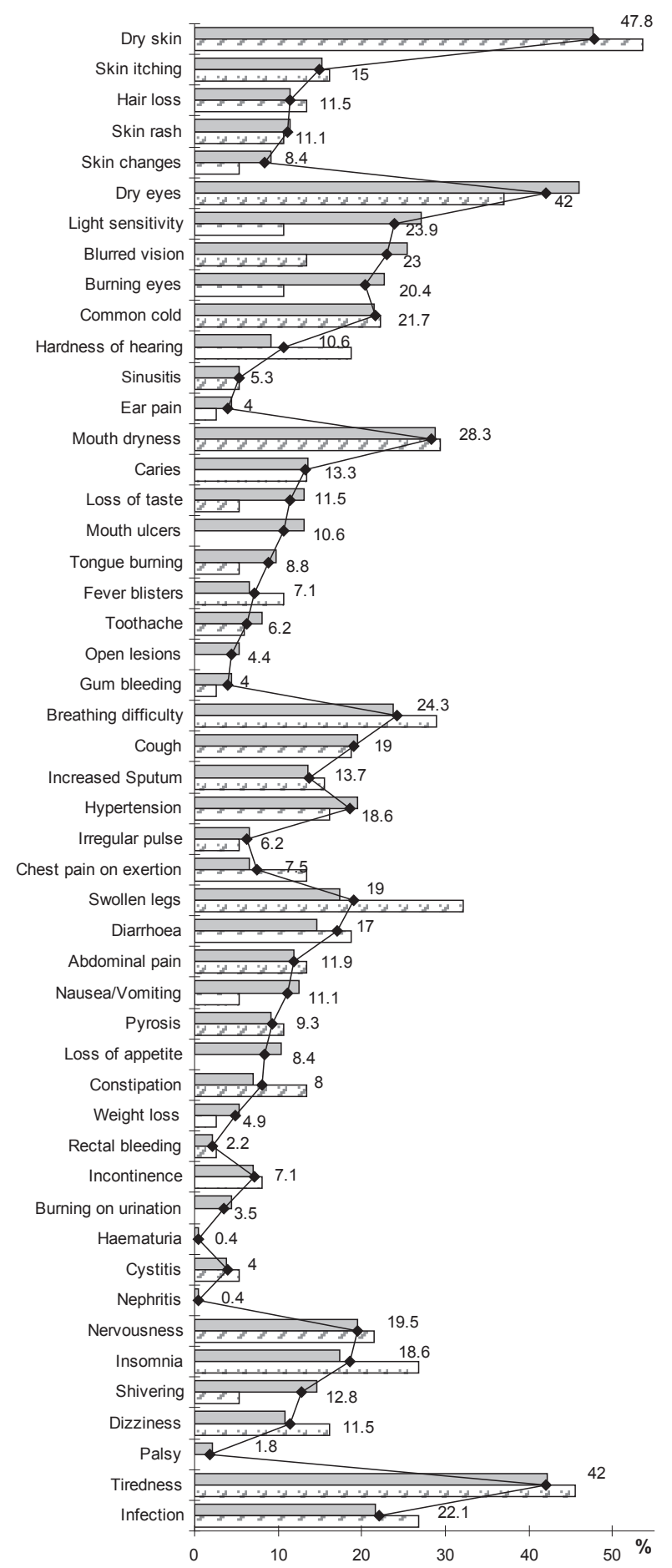

Figure 3: Percentages of physical symptoms in allogeneic patients $(n=188$; grey bars), autologous patients ( $n=38$; hatched bars) and in the total sample $(\mathrm{N}=226$; line graph with rhombus). Numbers adjacent each data point indicate the percentage distribution of a symptom in the whole sample.

Social well-being: Only 13 patients $(5.8 \%)$ reported problems connecting with social groups, although $15 \%(34 / 226)$ reported postHSCT changes in marital satisfaction. Of thirty who supplied details of the changes affecting them and their significant others most, 5 cited illness, 7 separation, 8 problems with sexuality or fertility, and 10 decreases in mutually beneficial emotional exchanges.
Infertility and sexuality: Approximately $20 \%$ of women (21/104) and men (24/122) reported decrease in sexual interest. Of 104 female responders, $37.5 \%$ claimed diminished vaginal lubrication, with increased vaginal discharge reported by $9.6 \%$. Hot flashes were indicated by $25 \%$ of women, who had an average age of 45.38 $(\mathrm{SD}=11.14)$. Painful intercourse was reported by $18.3 \%$ of women. Only 4 reported itching of the vagina. Comparing the occurrence of single symptoms in autologous and allogeneic transplanted women and between the different post-HSCT time groups, no differences were found.

Regarding male sexuality, $23.8 \%$ of 122 male responders reported erectile dysfunction. The mean age in this group was 51 (SD 11.9), compared to 47 years (SD 13.5) in men reporting no erectile dysfunction. Erectile dysfunction was reported equally in autologous and allogeneic transplant recipients $(\mathrm{p}=0.665)$ and in the four postHSCT time groups $(\mathrm{p}=0.444)$.

Questions concerning the desire to conceive were noted by three men (mean age 40.6 years, SD 6.4) and four women (mean age 26.5 years SD 7.2). Of the entire sample, 8 patients (3.5\%) wished to have advice from an expert in sexuality and/or fertility matters.

Appraisal of returning to normal performance regarding time span after allogeneic or autologous HSCT: As shown in figure 4 , concerning appraisals of 'having returned to normal' there were no significant differences between allogeneic and autologous patients either within or between post-HSCT time spans.

\section{Discussion}

This study is one of the few to report findings generated by patient self-report instruments used in clinical follow-up and focusing on post-HSCT symptoms and concerns. The high number of symptoms and concerns observed here illustrates the diversity of this patient population's needs. In light of the Institute of Medicine's latest 'From Cancer Patient to Cancer Survivor: Lost in Transition' report [26], it highlights transplant centers' responsibility to provide ongoing surveillance, care and information on available psychosocial and

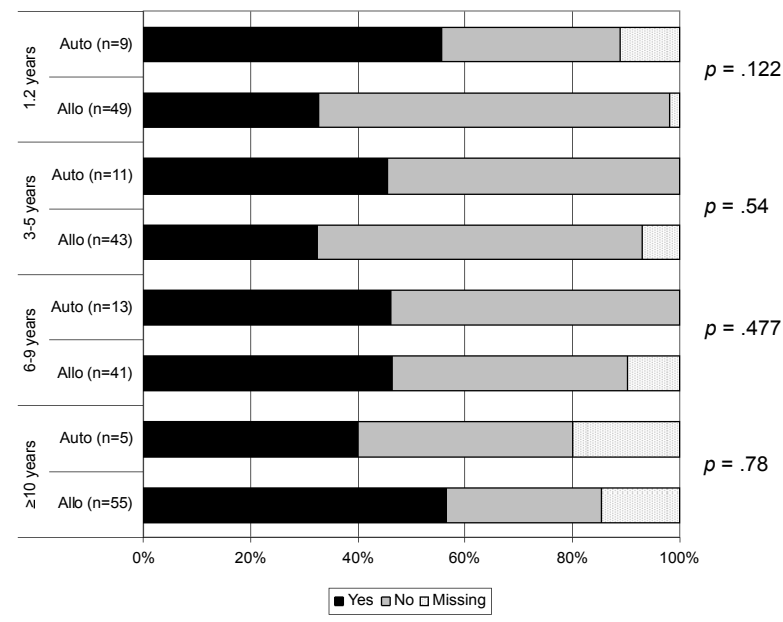

${ }^{a}$ Chi Square Test

Figure 4: The response of patients $(\mathrm{N}=226)$ to the question 'Do you feel completely back to normal and able to meet the daily demands required to do your job or housework? ' is shown, dependent on transplant type and length of follow up. In view of follow-up time, no significant differences were found between allogeneic and autologous patients ${ }^{\mathrm{a}}$ 
practical resources. It is becoming increasingly clear that complex care for HSCT patients requires a chronic care follow-up model that integrates comprehensive management not only of medical but also of psychosocial aspects, while reinforcing continuity of care and support regarding patient self-management and decision making. This contrasts with the acute care model currently prevalent, which has thus far failed to adequately address such issues [27].

In contrast to a number of earlier studies, we found no notable differences in the number of physical and emotional symptoms reported by autologous and allogeneic patients [28-30], thereby adding to a growing evidence base that the two patient groups have equal needs for long-term follow-up care $[4,15]$. One possible explanation for the equal number of symptoms between groups detected by our study might be the significantly higher age of autologous HSCT patients ( $\sim 10$ years) as well as the smaller sample size of this group. Higher age at transplantation remains a risk factor linked with more severe late effects and shorter post-transplant survival [31]. Due to the increasing relaxation of upper age limits for HSCT, the proportion of survivors with multiple morbidities is growing. Considering the ongoing discussion regarding differences in follow-up needs between allogeneic and autologous recipients, our results indicate the need for life-long follow-up of both groups.

The data reported in this study describes no notable differences in numbers of symptoms depending on time post-transplantation. Several studies, both cross-sectional and longitudinal in design, support our findings, as they also indicate significant proportions of patients suffering persistent symptoms and/or developing new ones. $[4,15,32,33]$ In comparison to control groups, HSCT recipients experience significantly more long-term symptoms that might result in inability to work, financial or insurance problems, and barriers to resuming normal everyday lives [34]. A cumulative burden of chronic health conditions evolving with increasing time after transplantation might account for the stable number of symptoms detected in our study. This explanation is supported by a recent cross-sectional casecontrol study showing that the incidence of any given chronic health condition in 1022 allogeneic and autologous stem cell transplant recipients increased from $32 \%$ at 2 years post-transplant to $59 \%$ at 10 years [35]. Overall, survivors were twice as likely as their matched siblings to develop a chronic condition, and 3.5 times more likely to develop a severe/life threatening condition.

Another important observation arising from the current study was that, as follow-up time increases, though the number of patients who gave positive appraisals of their performance and 'returning to normality' increased, a considerable proportion still reported not having regained their pre-transplant performance. The low rate of positive agreement to this question $(32.7 \%-56.4 \%)$ contrasts somehow with findings from an earlier longitudinal study in which $63 \%$ to $68 \%$ of two year survivors 'felt that they had returned to old selves' [15]. Besides the wording and scoring differences between the two studies' questionnaire items, we suggest that our study's low positive response rate reflected the dynamic that, with increasing time post-transplant, survivors increasingly accept that they might never again experience the 'normality of pre-transplant life'. This possibility has recently been a topic of considerable discussion among clinicians and researchers, some of whom have suggested that negative changes and restrictions due to long-term effects of prior or chronic health conditions are outweighed by the survivors' gratitude for being alive [36,37].

Integrating a self-report survey into clinical follow-up care to assess symptoms and concerns might provide a more complete picture of patients' health status, particularly regarding late effects and co- morbidities. For instance, in our study, eye-related symptoms were frequently mentioned by patients $(59.3 \%)$. These might be associated with common late effects such as sicca syndrome, retinopathy or cataract, for which early recognition and treatment could be extremely beneficial [38]. At present, the systematic use of self-reports in HSCT follow-up is rare. However, according to our clinical experience and increasing evidence from different oncology disciplines, while patient self-reports in follow-up care are arguably both feasible and beneficial, a need remains for research demonstrating their impacts on patient outcomes [39].

This study's findings should be interpreted in light of the following limitations. This was a single-centre cross-sectional study examining a heterogeneous sample of HSCT patients regarding disease, treatment history and co-morbidities. We admittedly did not perform multivariate analyses, which would have accounted for the simultaneous effects of diverse variables on the responses of interest. Also, non-German or non-French native speakers were under-represented in the sample, as the questionnaires were only available in these two languages. In order to enhance the participation of foreign language speakers known to be at risk for health disparities [40], we suggest supplying multilingual questionnaires and the assistance of professional interpreters as appropriate.

Critical comparison of this study's survey with the HSCT Assist model showed that the Assist model's domains and their subordinated indicators were only partially addressed. For example, the domains of health behaviour and spiritual well-being were completely missing and, in view of other domains, including physical-well being, for example, no assessment was included of muscle cramps, numbness and joint pain, although these are possible indicators of common musculoskeletal late effects such as myopathy, fibromyalgia, osteoporosis, scleroderma, strictures, fasciitis or neuropathy [41] The lack of such important issues calls for an adaptation of the survey before any future use.

The U.S. Food and Drug Administration outline new standards for self-report endpoints in clinical studies [42]. The generation of self report items should be based on qualitative work, i.e., derived from patient interviews, expert opinion and evidence in the literature. For example, the Patient-Reported Outcomes version of the Common Terminology Criteria for Adverse Events (PRO-CTCAE) provides a solid basis for the development of self-report measures assessing acute or late adverse effects of treatment from the patient's perspective. To develop the PRO-CTCAE symptom item bank based on the wellestablished CTCTAE terminology, Basch et al. [43] employed rigorous research steps, including the development of a conceptual framework, item selection and refinement via cognitive patient interviews and an expert survey, along with careful psychometric testing.

Optimally, the follow-up of HSCT patients should be based on a combination of systematic self-reporting and objective diagnostics. This approach would contribute to patient care quality by detecting health changes and nascent problems undetectable via clinical testing, leading to early treatment and hence to improved patient outcomes, e.g., reduced symptoms, increased health-related quality of life and enhanced patient satisfaction [6].

\section{Conclusion}

A clinical self-report questionnaire used in the follow-up of HSCT recipients showed high frequencies of diverse symptoms and patient related concerns. However, no significant differences could be found between autologous and allogeneic recipients. The results indicate a need for continuous monitoring of both groups, which will allow timely and effective interventions to prevent or alleviate late effects following HSCT. 
Citation: Kirsch M, Halter J, Geest SD (2012) Self-Reported Symptoms and Concerns in Long-Term Survivors Attending Follow-Up Visits after Hematopoietic Stem Cell Transplantation: A Cross-Sectional Single Center Evaluation in Switzerland. J Nurs Care 1:116. doi:10.4172/21671168.1000116

Page 7 of 7

\section{Acknowledgements}

We give special thanks to the patients receiving follow-up care at the USB and the healthcare team of the USB outpatient clinic. We are also grateful to Isabe Lehmann for her help with data collection, and to Professor Dr. Catherine Nissen for her thoughtful review of an earlier version of this manuscript.

\section{References}

1. Copelan EA (2006) Hematopoietic stem-cell transplantation. N Engl J Med 354: 1813-26

2. Bhatia S, Francisco L, Carter A, Sun CL, Baker KS, et al. (2007) Late mortality after allogeneic hematopoietic cell transplantation and functional status of longterm survivors: report from the Bone Marrow Transplant Survivor Study. Blood 110: 3784-3792.

3. Syrjala KL, Langer SL, Abrams JR, Storer B, Sanders JE, et al. (2004) Recovery and long-term function after hematopoietic cell transplantation for leukemia or lymphoma. JAMA 291: 2335-2343.

4. Rizzo JD, Wingard JR, Tichelli A, Lee SJ, Van Lint MT, et al. (2006) Recommended screening and preventive practices for long-term survivors after hematopoietic cell transplantation: joint recommendations of the European Group for Blood and Marrow Transplantation, the Center for International Blood and Marrow Transplant Research, and the American Society of Blood and Marrow Transplantation. Biol Blood Marrow Transplant 12: 138-151.

5. Lipscomb J, Gotay CC, Snyder CF (2007) Patient-reported outcomes in cancer: a review of recent research and policy initiatives. CA Cancer J Clin 57: 278-300.

6. Basch E, Jia X, Heller G, Barz A, Sit L, et al. (2009) Adverse symptom event reporting by patients vs clinicians: relationships with clinical outcomes. J Nat Cancer Inst 101: 1624-1632.

7. Efficace F, Novik A, Vignetti M, Mandelli F, Cleeland CS (2007) Health-related quality of life and symptom assessment in clinical research of patients with hematologic malignancies: where are we now and where do we go from here? Haematologica 92: 1596-1598.

8. Grunfeld E (2006) Looking beyond survival: how are we looking at survivorship? $\mathrm{J}$ Clin Oncol 24: 5166-5169.

9. Parkes CM (1971) Psycho-social transitions: A field for study. Soc Sci Med 5: 101-115.

10. Lee SJ, Loberiza FR, Antin JH, Kirkpatrick T, Prokop L, et al. (2005) Routine screening for psychosocial distress following hematopoietic stem cell transplantation. Bone Marrow Transplant 35: 77-83.

11. Hjermstad MJ, Knobel H, Brinch L, Fayers PM, Loge JH, et al. (2004) A prospective study of health-related quality of life, fatigue, anxiety and depression 3-5 years after stem cell transplantation. Bone Marrow Transplant 34: 257-266.

12. Gruber U, Fegg M, Buchmann M, Kolb HJ, Hiddemann W (2003) The long-term psychosocial effects of haematopoetic stem cell transplantation. Eur $\mathrm{J}$ Cancer Care 12: 249-256.

13. Rusiewicz A, DuHamel KN, Burkhalter J, Ostroff J, Winkel G, et al. (2008) Psychological distress in long-term survivors of hematopoietic stem cell transplantation. Psychooncology 17: 329-337.

14. Kiss TL, Abdolell M, Jamal N, Minden MD, Lipton JH, et al. (2002) Long-term medical outcomes and quality-of-life assessment of patients with chronic myeloid leukemia followed at least 10 years after allogeneic bone marrow transplantation. J Clin Oncol 20: 2334-2343.

15. Lee SJ, Fairclough D, Parsons SK, Soiffer RJ, Fisher DC, et al. (2001) Recovery after stem-cell transplantation for hematologic diseases. J Clin Oncol 19: $242-252$.

16. Humphreys CT, Tallman B, Altmaier EM, Barnette V (2007) Sexual functioning in patients undergoing bone marrow transplantation: a longitudinal study. Bone Marrow Transplant 39: 491-496.

17. Syrjala KL, Kurland BF, Abrams JR, Sanders JE, Heiman JR (2008) Sexual function changes during the 5 years after high-dose treatment and hematopoietic cell transplantation for malignancy, with case-matched controls at 5 years. Blood 111: 989-996.

18. Hammond C, Abrams JR, Syrjala KL (2007) Fertility and risk factors for elevated infertility concern in 10-year hematopoietic cell transplant survivors and casematched controls. J Clin Oncol 25: 3511-3517.

19. Harder H, Cornelissen JJ, Van Gool AR, Duivenvoorden HJ, Eijkenboom WM et al. (2002) Cognitive functioning and quality of life in long-term adult survivors of bone marrow transplantation. Cancer 95: 183-192.

20. Bishop MM, Lee SJ, Beaumont JL, Andrykowski MA, Rizzo JD, et al. (2010) The preventive health behaviors of long-term survivors of cancer and hematopoietic stem cell transplantation compared with matched controls. Biol Blood Marrow Transplant 16: 207-214.

21. Sherman AC, Plante TG, Simonton S, Latif U, Anaissie EJ (2009) Prospective study of religious coping among patients undergoing autologous stem cell transplantation. J Behav Med 32: 118-128.

22. Syrjala KL, Stover AC, Yi JC, Artherholt SB, Abrams JR (2010) Measuring social activities and social function in long-term cancer survivors who received hematopoietic stem cell transplantation. Psychooncology 19: 462-471.

23. Mor V, Laliberte L, Morris JN, Wiemann M (1984) The Karnofsky Performance Status Scale. An examination of its reliability and validity in a research setting Cancer 53: 2002-2007

24. Filipovich AH (2008) Diagnosis and manifestations of chronic graft-versus-hos disease. Best Pract Res Clin Haematol 21: 251-257.

25. Storey JD, Tibshirani R (2003) Statistical significance for genomewide studies Proc Natl Acad Sci U S A 100: 9440-9445.

26. Maria Elizabeth Hewitt, Sheldon Greenfield, Ellen Stovall, National Cance Policy Board (U.S.). Committee on Cancer Survivorship: Improving Care and Quality of Life (2006) From Cancer Patient to Cancer Survivor: Lost in Transition, National Academies Press, Washington.

27. Wagner EH, Austin BT, Von Korff M (1996) Improving outcomes in chronic illness. Manag Care Q 4: 12-25.

28. Andrykowski MA, Brady MJ, Greiner CB, Altmaier EM, Burish TG, et al. (1995) 'Returning to normal' following bone marrow transplantation: outcomes, expectations and informed consent. Bone Marrow Transplant 15: 573-581.

29. Zittoun R, Suciu S, Watson M, Solbu G, Muus P, et al. (1997) Quality of life in patients with acute myelogenous leukemia in prolonged first complete remission after bone marrow transplantation (allogeneic or autologous) or chemotherapy: a cross-sectional study of the EORTC-GIMEMA AML 8A trial. Bone Marrow Transplant 20: 307-315.

30. Andrykowski MA, Greiner CB, Altmaier EM, Burish TG, Antin JH, et al. (1995) Quality of life following bone marrow transplantation: findings from a multicentre study. Br J Cancer 71: 1322-1329.

31. Deeg HJ, Sandmaier BM (2010) Who is fit for allogeneic transplantation? Blood 116: $4762-4770$

32. Bush NE, Donaldson GW, Haberman MH, Dacanay R, Sullivan KM (2000) Conditional and unconditional estimation of multidimensional quality of life after hematopoietic stem cell transplantation: a longitudinal follow-up of 415 patients. Biol Blood Marrow Transplant 6: 576-591.

33. Bush NE, Haberman M, Donaldson G, Sullivan KM (1995) Quality of life of 125 adults surviving $6-18$ years after bone marrow transplantation. Social Science Medicine 40: 479-490

34. Syrjala KL, Langer SL, Abrams JR, Storer BE, Martin PJ (2005) Late effects of hematopoietic cell transplantation among 10 -year adult survivors compared with case-matched controls. J Clin Oncol 23: 6596-6606

35. Sun CL, Francisco L, Kawashima T, Leisenring W, Robison LL, et al. (2010) Prevalence and predictors of chronic health conditions after hematopoietic cell transplantation: a report from the Bone Marrow Transplant Survivor Study. Blood 116: 3129-3139.

36. Mosher CE, DuHamel KN, Rini C, Corner G, Lam J, et al. (2011) Quality of life concerns and depression among hematopoietic stem cell transplant survivors. Support Care Cancer 19: 1357-1365.

37. Bishop MM, Curbow BA, Springer SH, Lee JA, Wingard JR (2011) Comparison of lasting life changes after cancer and BMT: perspectives of long-term survivors and spouses. Psychooncology 20: 926-934.

38. Tabbara KF, Al-Ghamdi A, Al-Mohareb F, Ayas M, Chaudhri N, et al. (2009) Ocular findings after allogeneic hematopoietic stem cell transplantation. Ophthalmology 116: 1624-1629.

39. Luckett T, Butow PN, King MT (2009) Improving patient outcomes through the routine use of patient-reported data in cancer clinics: future directions. Psychooncology 18: 1129-1138.

40. Armenian SH, Sun CL, Teh JB, Arora M, Baker KS, et al. (2010) Ethnic differences in chronic health conditions after hematopoietic cell transplantation: a report from the bone marrow transplant survivor study. Cancer 116: 4152 4159

41. Syrjala KL, Yi JC, Artherholt SB, Stover AC, Abrams JR (2010) Measuring musculoskeletal symptoms in cancer survivors who receive hematopoietic cell transplantation:. J Cancer Surviv 4: 225-235.

42. US Department of Health and Human Services Food and Drug Administration Center for Drug Evaluation and Research (CDER), Center for Biologics Evaluation and Research (CBER), Center for Devices and Radiological Health (CDRH) (2009) Guidance for Industry: Patient-Reported Outcome Measures: Use in Medical Product Development to Support Labeling Claims, Silver Spring

43. Basch $E$ (2010) The missing voice of patients in drug-safety reporting. N Eng J Med 362: 865-869. 